\title{
REDUÇÃO FOLIAR NA PRODUÇÃO E SOBREVIVÊNCIA DE MINIESTACAS DE Eucalyptus urophylla var. platyphylla
}

Jhonata Santos Santana1, Elton Ferreira Lima², Paulo Roberto Moreira Brandão³, Wilson Araújo da Silva ${ }^{4}$, Mydilany Carneiro Fernandes ${ }^{5}$

1. Bolsista de Apoio Técnico Institucional II (BATI II), Engenheiro Agrônomo, Universidade Estadual do Maranhão-UEMA. Imperatriz, MA. agro.starf@gmail.com

2. Bolsista de iniciação científica, Graduando em Engenharia Agronômica, Universidade Estadual da Região Tocantina do Maranhão-UEMASUL, Imperatriz, MA.

3. Graduado em Engenharia Agronômica na Universidade Estadual do Maranhão, Imperatriz, MA.

4. Doutor em Ciência do Solo, Engenheiro Agrônomo, Universidade Estadual do Maranhão, Imperatriz, MA.

5. Graduada em Ciências Biológicas na Universidade Estadual do Maranhão-UEMA, Imperatriz, MA.

Recebido em: 06/04/2018 - Aprovado em: 10/06/2018 - Publicado em: 20/06/2018 DOI: 10.18677/EnciBio_2018A72

\section{RESUMO}

A redução da área foliar é uma técnica bastante utilizada na produção de mudas de eucaliptos, cujo o propósito é reduzir a área de transpiração foliar e favorecer o molhamento do substrato. Assim, o presente estudo teve como objetivos avaliar os efeitos de diferentes níveis de redução foliar na produção e sobrevivência de miniestacas de eucalyptus urophylla var. platyphylla. O experimento foi conduzido sob condições controladas em viveiro no município de Cidelândia - MA, entre os dias 15 de setembro de 2016 e 26 de dezembro do mesmo ano, onde foram analisadas reduções foliares $(0 \% ; 25 \% ; 50 \% ; 75 \%$ e $100 \%)$, sob esquema de delineamento inteiramente casualizado (DIC), composto por cinco tratamentos e vinte repetições. Por se tratar de um experimento com tratamentos quantitativos foi feito o estudo de análise de variância (ANOVA) seguida de análise de regressão. Os parâmetros morfológicos avaliados foram: a altura da parte aérea $(\mathrm{H})$, diâmetro do colo (DC), relação altura diâmetro do colo (H:DC) e o fator sobrevivência. $O$ tratamento 2 (com $25 \%$ de redução foliar) de maneira geral foi o que se sobressaiu entre os demais tratamentos, sendo recomendado para a propagação de híbridos de Eucalyptus urophylla var. platyphylla.

PALAVRAS-CHAVE: sobrevivência, viveiro, transpiração foliar.

\section{FOLIAR REDUCTION IN THE PRODUCTION AND SURVIVAL OF MINIESTACES OF Eucalyptus urophylla var. platyphylla}

\begin{abstract}
The reduction of leaf area is a technique widely used in the production of eucalyptus seedlings, whose purpose is to reduce the area of leaf transpiration and favor wetting of the substrate. Thus, the present study had as objectives to evaluate the effects of different levels of leaf reduction on the production and survival of minicuttings of
\end{abstract}


eucalyptus urophylla var. platyphylla. The experiment was conducted under controlled conditions in a nursery in the municipality of Cidelândia - MA, between September 15, 2016 and December 26 of the same year, where foliar $(0 \%, 25 \%$, $50 \%, 75 \%$ and $100 \%$ ), under a completely randomized design (DIC), consisting of five treatments and twenty replications. Since it was an experiment with quantitative treatments, the analysis of variance (ANOVA) was performed, followed by regression analysis. The morphological parameters evaluated were: the height of the aerial part $(\mathrm{H})$, the diameter of the neck (DC), the height of the neck $(\mathrm{H}: \mathrm{DC})$ and the survival factor. The treatment 2 (with $25 \%$ of leaf reduction) in general was the one that stood out among the other treatments, being recommended for the propagation of hybrids of Eucalyptus urophylla var. platyphylla.

KEYWORDS: survival, nursery, leaf transpiration.

\section{INTRODUÇÃO}

As florestas plantadas, além de sua importância econômica, apresentam outros ganhos ambientais significativos, como a redução da pressão sobre as florestas nativas, contribuindo para a conservação destas (SCHUMACHER et al., 2013). O termo Eucalipto é a denominação popular de diversas espécies vegetais do gênero Eucalyptus (BUTRINOWSKI et al., 2013). O uso de espécies do gênero Eucalyptus é dos principais opções de abastecimento de matéria-prima das indústrias de siderurgia, papel e celulose, produção de madeira para serraria, mourões, compensados, e outros produtos requisitados ao setor florestal do país (FERREIRA et al., 2014).

As espécies de interesse econômico pertencentes ao gênero Eucalyptus assumiram o favoritismo dos investidores, tanto em razão às facilidades de cultivo quanto à adaptação, velocidade de crescimento e a flexibilidade no uso da madeira (BENIN et al., 2013). A produção de clones por meio da miniestaquia permitiu a intensificação dos plantios clonais no país, em proporções comerciais. Essa metodologia fortaleceu um dos "mercados florestais", que foi o aparecimento de vários viveiros autônomos (não dependentes das firmas florestais), que começaram a oferecer ao mercado milhares de mudas clonais de Eucalyptus ao ano (BATISTA et al., 2014).

O recurso de miniestaquia é o mais empregado pelas maiores empresas florestais do Brasil no processo de clonagem de genótipos selecionados de Eucalyptus, permitindo ganhos significativos de produtividade em razão do incremento dos índices de enraizamento e da diminuição do período de formação da muda em relação ao emprego da estaquia (BRONDANI et al., 2014). No processo de clonagem as miniestacas são obtidas de plantas chamadas de minicepas e cultivadas em minijardins clonais em hidroponia em valas de areia ou em tubetes sendo esta técnica a mais empregada no Brasil (ROCHA et al., 2015).

Objetivando obter melhores resultados tanto na produção quanto na qualidade nos processos de produção de mudas clonais encontram-se na literatura várias recomendações para o padrão de estacas, dentre estas está a técnica da redução foliar (SOUZA et al., 2013; MORAIS et al., 2014; STUEPP et al., 2015; CORREIA et al., 2015; DIAS et al., 2015; OLIVEIRA et al., 2015; LAFETÁ et al., 2016; ENGEL et al., 2016; NEUBERT et al., 2017; FREITAS et al., 2017).

De acordo com Souza et al., (2013) a técnica de redução da área foliar em produção de mudas está vinculada à cultura proveniente da técnica de macroestaquia, cujo o propósito é reduzir a área de transpiração foliar e impedir o efeito guarda-chuva, que é considerado um impedimento físico provocado pela a 
área foliar das estacas que dificulta o molhamento do substrato. Embora a estaquia ter se tornado o método de propagação vegetativa mais disseminada esta apresenta limitações de seu uso, principalmente devido a produção de mudas com sistema radicular de má qualidade (RAASCH et al., 2013).

Segundo Correia et al. (2015) a presença das folhas é de grande importância para o enraizamento das estacas, uma vez que a fotossíntese permite o acúmulo de carboidratos que propiciam o crescimento radicular. Entretanto Xavier et al. (2009), sugerem a produção de mudas a partir de estacas com dimensões variando entre 6 e $10 \mathrm{~cm}$, possuindo de um a dois pares de folhas, reduzindo à metade da área foliar. Já Alfenas et al. (2009) recomendam manter de dois a três pares de folhas possuindo metade da área foliar, mas sugerem que estacas com dois pares de folhas apresentam melhor enraizamento. Ao passo que Brondani et al. (2008) sugerem a utilização de estacas apresentando dois pares de folhas e com área foliar reduzida a $50 \%$.

No entanto segundo Paiva e Gomes (2011) é importante a existência de folhas em estacas, uma vez que produzem carboidratos, auxinas outras substâncias que favorecem o crescimento radicular, assim sugerem a utilização de estacas com duas a quatro gemas, mantendo-se as folhas, mas com $50 \%$ da área foliar.

Segundo Morais et al. (2014) a redução da área foliar em miniestacas é essencial para impedir o efeito "guarda-chuva", que prejudica a eficiência da irrigação, além de favorecer excesso de transpiração e o recurvamento das estacas. Entretanto, não se conhece até que ponto a redução da área foliar afeta a produção e a sobrevivência das miniestacas empregadas na produção de mudas. Assim o presente trabalho teve como objetivos avaliar os efeitos proporcionados pela técnica de redução foliar na produção e sobrevivência de miniestacas de Eucalyptus urophylla var. platyphylla.

\section{MATERIAL E MÉTODOS}

O experimento foi realizado em viveiro de produção de mudas de eucalipto no município de Cidelândia-MA (latitude $-05^{\circ} 09^{\prime} 08^{\prime \prime} S$ e longitude $-47^{\circ} 46^{\prime} 17^{\prime \prime} \mathrm{W}$ e altitude de $131 \mathrm{~m}$ ). Foi utilizado um minijardim clonal para a coleta das miniestacas apicais de híbrido de Eucalyptus urophylla var. Platyphylla, que ocorreu no dia 15 de setembro de 2016, e enviadas ao viveiro, devidamente identificadas, para enraizamento que durou cerca de 30 dias sob nevoeiro intermitente e aclimatadas à sombra por sete dias para posteriormente serem expostas a aclimatação a céu aberto. Após a passagem das mudas por todos esses processos, foram levadas a fase de crescimento e rustificação com duração em média de 45 dias. Passados os 100 dias as mudas foram levadas ao setor de expedição para a realização do estudo.

Os tubetes utilizados apresentavam modelo de seção circular, com quatro frisos internos longitudinais, com dimensões de $12,5 \mathrm{~cm}$ de altura, 2,8 cm de diâmetro na parte interna superior, com fundo aberto de aproximadamente $1 \mathrm{~cm}$ e com capacidade volumétrica de $50 \mathrm{~cm}^{3}$. O substrato apresentava composição de casca de coco, casca de arroz carbonizado e vermiculita nas proporções 20:40:40 com adubação de $2,4 \mathrm{~kg} \cdot \mathrm{m}^{-3}$ contendo $13 \%$ de $\mathrm{N} ; 6 \% \mathrm{P}_{2} \mathrm{O}_{5} ; 16 \% \mathrm{~K}_{2} \mathrm{O} ; 1,4 \% \mathrm{Mg} ; 10 \%$ $\mathrm{S} ; 0,26 \% \mathrm{Fe} ; 0,02 \% \mathrm{~B} ; 0,05 \% \mathrm{Cu} ; 0,06 \% \mathrm{Mn}$ e $0,015 \% \mathrm{M}$, sendo este o mesmo utilizado para a produção de mudas comerciais.

As miniestacas coletadas apresentavam altura em torno $4 \mathrm{~cm}$ e 3 pares de folhas completos onde tiveram suas bases colocadas a uma profundidade média 1,5 cm no centro dos tubetes com capacidades já citadas anteriormente. Logo após a 
coleta, com o uso de tesoura previamente esterilizada, foram submetidas aos tratamentos 1, 2, 3, 4 e 5 com $0 \%, 25 \%, 50 \%, 75 \%$ e 100\% de redução foliar, respectivamente, como mostra a Figura 1, frisando a redução realizada nas folhas das estacas e a Figura 2 a redução foliar por tratamento, em que o tratamento $1 \mathrm{com}$ $0 \%$ de redução foliar constituiu a testemunha do estudo.

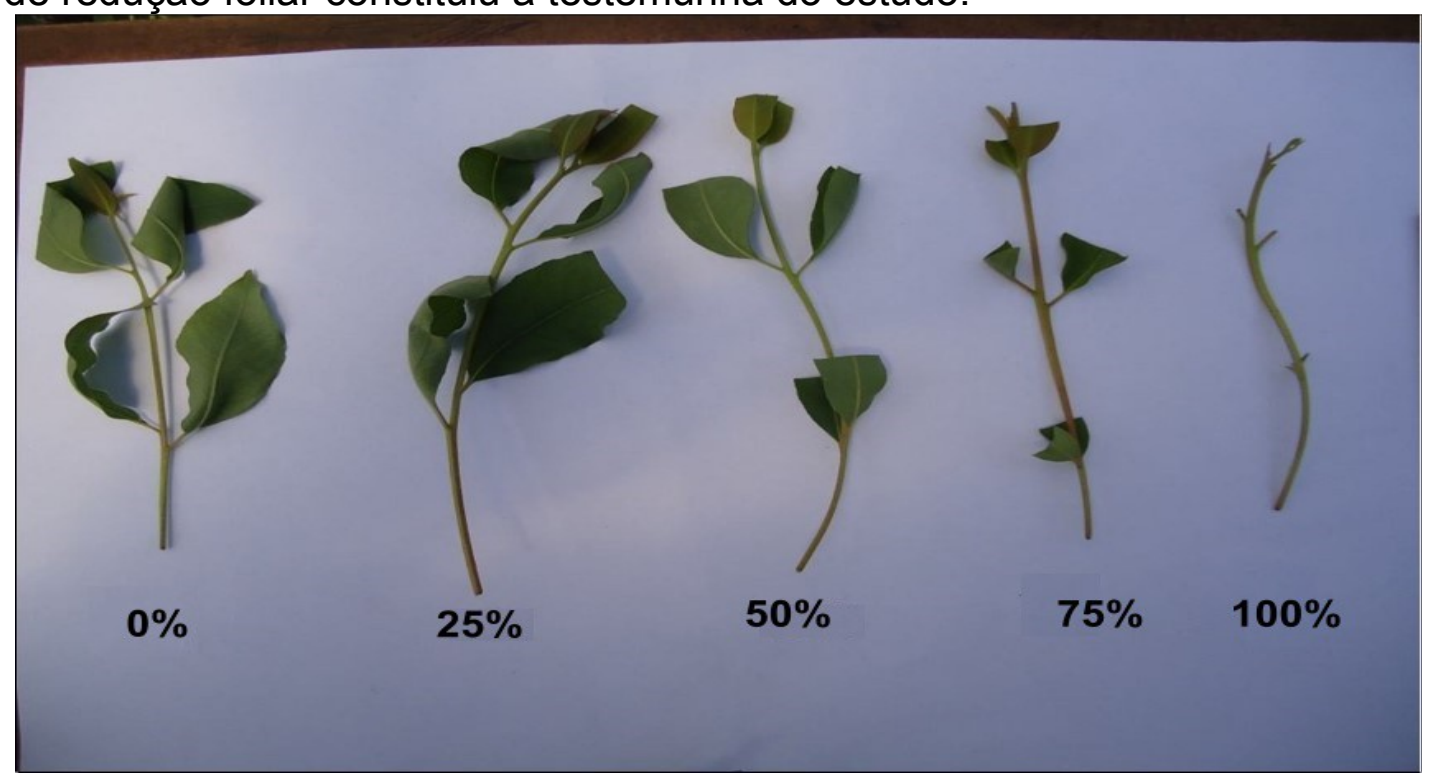

FIGURA 1- Disposição dos tratamentos nas miniestacas coletadas.

FONTE: Autores (2018).

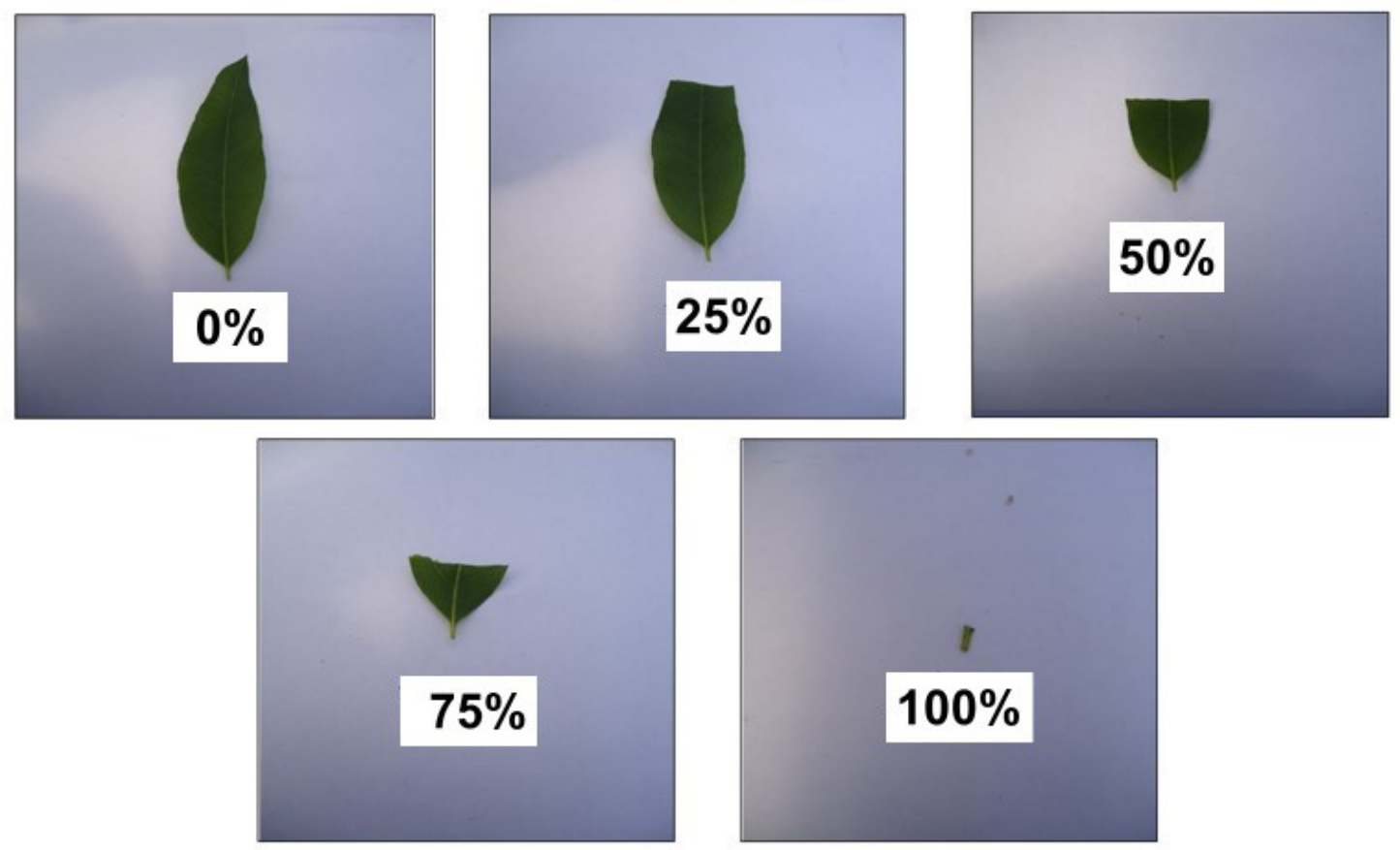

FIGURA 2- Disposição dos tratamentos nas folhas. FONTE: Autores (2018).

O delineamento experimental utilizado foi do tipo inteiramente casualizado (DIC), composto por cinco tratamentos $(0 \%, 25 \%, 50 \%, 75 \%$ e $100 \%$ de redução foliar) e 20 repetições, cada unidade experimental foi constituída de duas miniestacas, dispostas ao acaso, totalizando 100 unidades experimentais, onde as plantas úteis avaliadas foram as miniestacas centrais da bandeja, desconsiderando a bordadura, para evitar distorções nas respostas dos tratamentos. As variáveis ENCICLOPÉDIA BIOSFERA, Centro Científico Conhecer - Goiânia, v. 15 n.27; p. 65 
observadas em cada unidade experimental, foram: a altura da parte aérea $(\mathrm{H})$ em $\mathrm{cm}$, diâmetro do colo (DC) em $\mathrm{mm}$, relação entre altura da parte aérea e diâmetro do coleto (H:DC) e sobrevivência aos 100 dias.

Para a medição da altura da parte aérea, foi medida a distância entre a superfície do tubete até o último par de folhas lançadas dos ramos. Para esta avaliação, foi utilizada uma régua graduada para medir as 10 plantas centrais de cada tratamento. A medição do diâmetro do coleto (DC em $\mathrm{mm}$ ) foi realizada utilizando-se um paquímetro digital ao nível do substrato.

A relação altura da parte aérea e diâmetro do colo $(\mathrm{H}: \mathrm{DC})$ tem como objetivo avaliar o quociente de robustez, que é um dos parâmetros mais relevantes como indicador de qualidade de mudas, pois fornece a informação de quanto a muda esta delgada (JOHNSON; CLINE, 1991).

Sua determinação foi realizada dividindo-se a altura da parte aérea $(\mathrm{H})$ em $\mathrm{cm}$, pelo o diâmetro do colo (DC) em $\mathrm{mm}$. O fator sobrevivência de mudas que é expresso em porcentagem foi obtido pela relação entre o total de mudas plantadas e total de mudas que sobreviveram após 100 dias de estudo, sendo determinado através da diagnose visual.

Por se tratar de um experimento com tratamentos quantitativos (porcentagens de redução foliar) realizou-se primeiramente o estudo de análise de variância (ANOVA) da regressão, e no caso de significativo procedeu-se com o estudo da regressão para verificar a equação matemática que apresenta melhor a variável estudada, obtendo-se o ajuste e coeficientes de determinação (R2). Para análise estatística dos dados provenientes das medições do estudo, utilizou-se o programa ASSISTAT 7.6.

\section{RESULTADOS E DISCUSSÃO}

\section{Altura da parte aérea $(\mathrm{H})$}

A redução foliar influenciou significativamente a variável altura da parte aérea. O modelo polinomial que melhor se ajustou ao comportamento da variável altura da planta em função da redução foliar, foi o quadrático (Figura 3).

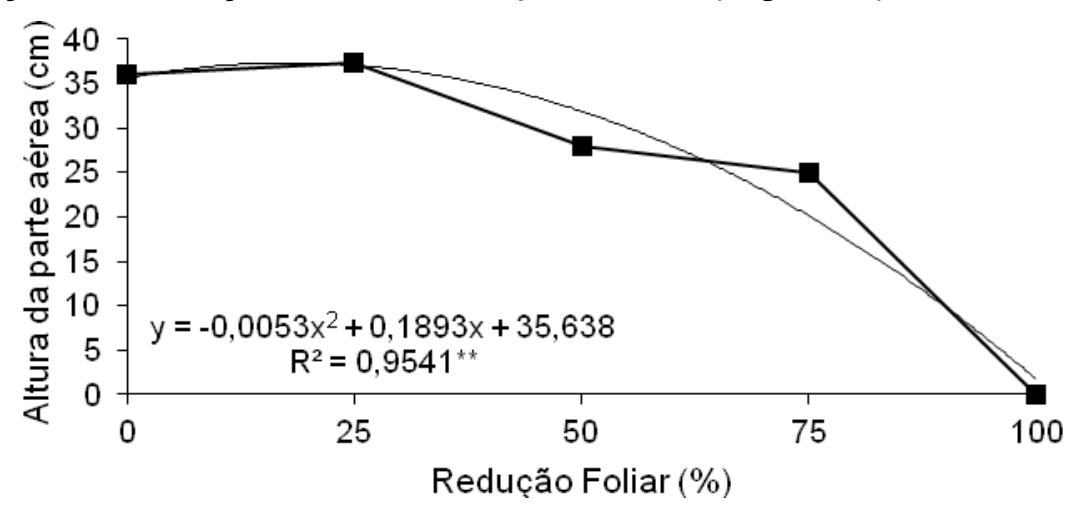

FIGURA 3- Altura da parte aérea das mudas de eucalipto em função da redução foliar. ** significativo a $1 \%$.

FONTE: Autores (2018).

Verifica-se, pela curva de regressão, que com $0 \%$ de redução foliar a altura média obtida foi de $36,11 \mathrm{~cm}$ e com $25 \%$ de redução foliar a altura média foi de 37,42 $\mathrm{cm}$, ou seja a redução foliar promoveu um aumento na altura de plantas, entretanto, 
houve redução a partir daí nos tratamentos seguintes de $50 \%, 75 \%$ e $100 \%$ de redução foliar, caracterizando uma curva de tendência quadrática de comportamento, pela diminuição da variável altura de plantas com o aumento da porcentagem de redução foliar, que pode ter sido decorrente da redução excessiva do mesofilo é o tecido mais ativo na realização da fotossíntese que prejudicou a produção de fotoassimilados resultando um decrescimento de altura.

De acordo com Souza et al., (2013) a manutenção das folhas ou de pelo menos parte delas favorece o processo de enraizamento das estacas, em razão da produção de carboidratos provenientes da fotossíntese, além da produção de hormônios como as auxinas que também são importantes no enraizamento.

Resultado semelhante aos obtidos nesse estudo foi encontrado no trabalho de Santana et al. (2010) onde observaram que o tratamento de $25 \%$ de redução da área foliar promoveu incremento na altura de plantas em relação a testemunha com $0 \%$ de redução foliar. Essa redução foliar promove maior incremento na altura de plantas em razão da diminuição da área de evaporação foliar no período crítico em que estaca está realizando o processo emissão e formações de raízes, promovendo equilíbrio necessário para o desenvolvimento da muda.

\section{Diâmetro do coleto (DC)}

A altura e diâmetro do colo são parâmetros de fácil avaliação, constituídos de testes não destrutivos, que são bastante empregados para estimar o padrão de qualidade das mudas produzidas nos viveiros (SOUZA et al., 2013). A redução foliar influenciou significativamente a variável diâmetro do colo (DC). O modelo polinomial que melhor se ajustou ao comportamento da variável diâmetro do colo em função da redução foliar, foi o quadrático (Figura 4).

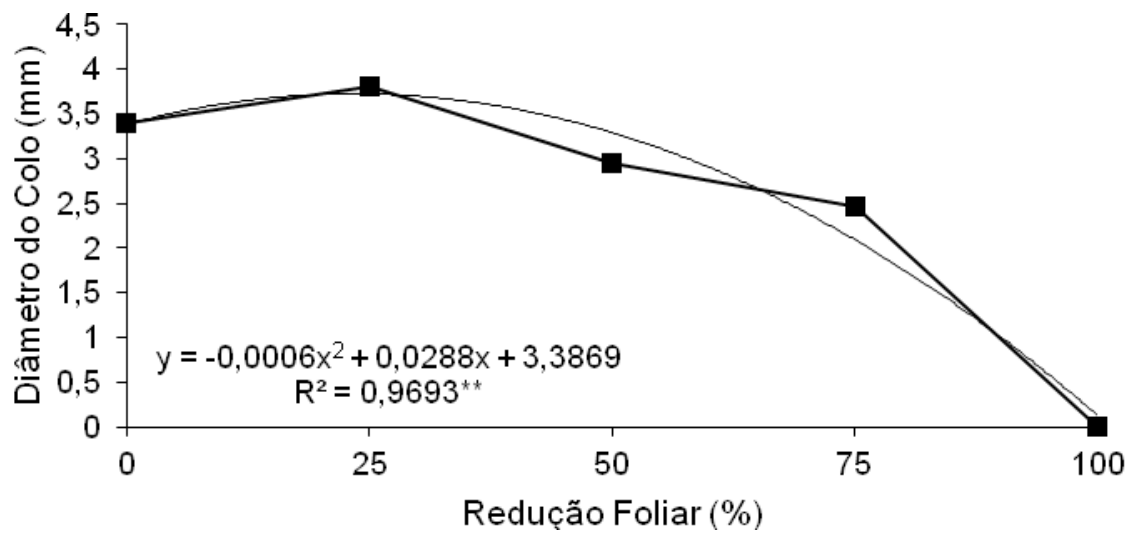

FIGURA 4- Diâmetro do colo das mudas de eucalipto em função da redução foliar. ${ }^{* *}$ significativo a $1 \%$.

FONTE: Autores (2018).

Para a variável diâmetro do colo observou-se efeito quadrático em função das porcentagens de redução foliar, em que o tratamento 2 (25\% de redução foliar) teve a maior média entre os tratamentos, com 3,81 $\mathrm{mm}$ de diâmetro de colo, e o tratamento 1 testemunha (0\% de redução foliar) apresentou 3,40 $\mathrm{mm}$ de média. Já os outros tratamentos, $3 ; 4$ e 5 todos ficaram com médias menores que a testemunha 2,$95 ; 2,46$ e $0,00 \mathrm{~mm}$ de espessura.

Este parâmetro morfológico é bastante utilizado na análise da qualidade das mudas, onde Gomes (2002), Alfenas (2009) e Santana et al. (2010) em seus 
trabalhos avaliaram o mesmo parâmetro e conforme estes autores os melhores resultados obtidos por eles nas medições ficaram em torno de 2 a $3 \mathrm{~mm}$ de espessura do colo da planta. Vale ressaltar que o tratamento 5 (100\% de redução foliar), não foi avaliado, pois houve $100 \%$ de mortalidade. Portanto, assim como nos trabalhos de Santana et al. (2010), o melhor tratamento foi o de $25 \%$ de redução foliar que se sobressaiu em relação aos demais.

\section{Relação altura x diâmetro do colo (H:DC)}

A redução foliar influenciou significativamente a variável altura $x$ diâmetro do colo (H:DC). O modelo polinomial que melhor se ajustou ao comportamento da variável diâmetro do colo em função da redução foliar, foi o quadrático (Figura 5).

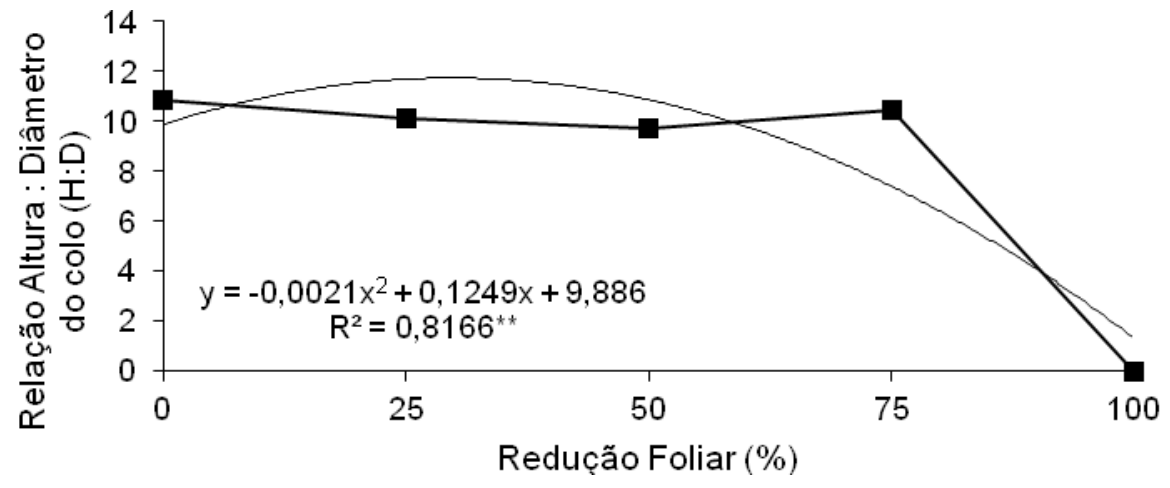

FIGURA 5- Relação altura : diâmetro em função da redução foliar. ** significativo a $1 \%$.

FONTE: Autores (2018).

Para a relação altura $x$ diâmetro do coleto $(\mathrm{H}: \mathrm{C})$ observou-se efeito quadrático em função das porcentagens de redução foliar, e o valor máximo de 10,85 obtido com a redução foliar de $0 \%$, enquanto o tratamento 2 apresentou apenas 10,14 de média.

Os tratamentos 3,4 e 5 ficaram com médias 9,75; 10,46 e 0,00 respectivamente. Segundo Carneiro (1995), o valor mínimo de H:C para se verificar este equilíbrio de crescimento das mudas, é de 7,5 para espécies do gênero Eucalyptus. Já para espécies Pinnus sp, este valor pode variar entre 5,1 e 8,1. Considerando estes limites para os resultados obtidos nesse estudo, todos os tratamentos, exceto o tratamento 5 de $100 \%$ de redução foliar, resultarem em mudas de bom padrão de qualidade, pois apresentaram valores inferiores ao limite mínimo.

De acordo com Carneiro (1995), esta variável constitui um dos mais importantes parâmetros morfológicos, para avaliar a qualidade da mudas, em que o valor resultante exprime o equilíbrio de crescimento, relacionando os dois fatores em um só índice. Portanto, o tratamento que apresentou o maior quociente de robustez, foi o tratamento 1 , a testemunha (com $0 \%$ de redução foliar), com relação $(H: D)$ máxima de 10,85.

\section{Sobrevivência aos 100 dias.}

Apesar de não ser um parâmetro morfológico, a sobrevivência das mudas não deixa de ser um fator a ser avaliado, pois segundo Sperandio et al. (2011), no setor 
de produção de mudas se espera obter altos índices de sobrevivência das mudas, pois assim, evitará gastos desnecessários com mão-de-obra, substratos, manutenção de infraestrutura e água, ou seja, o objetivo é sempre alcançar a maior eficiência na produção.

Com base nos resultados da análise de variância observou-se efeito significativo a $1 \%$ para a variável de Sobrevivência de mudas a interpretação da análise de variância mostra que houve ajuste para o modelo quadrático (Figura 6).

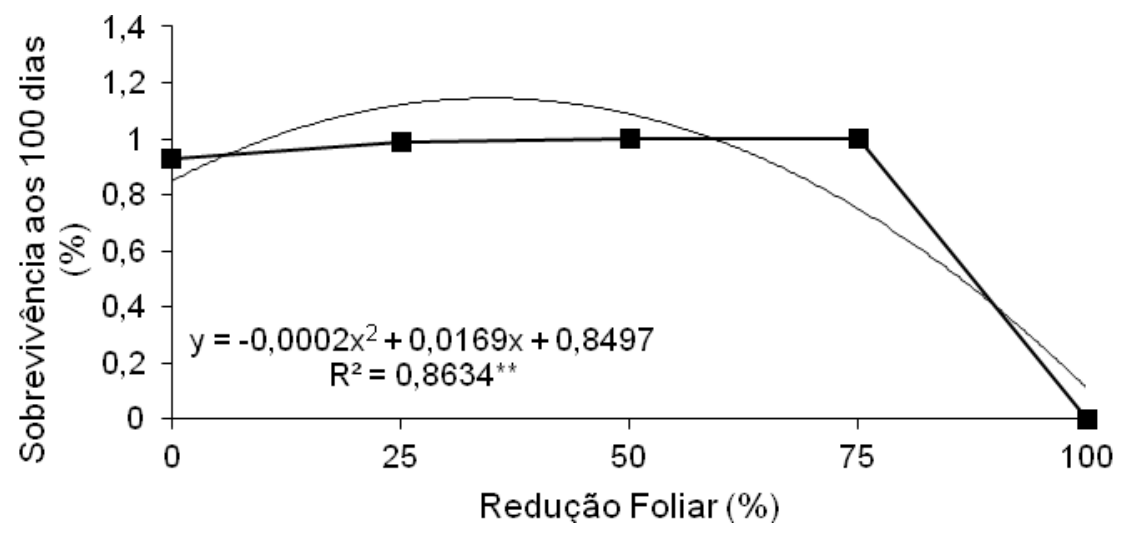

FIGURA 6- Sobrevivência de mudas de eucalipto aos 100 dias em função da redução foliar. ** significativo a $1 \%$.

FONTE: Autores (2018).

Os tratamentos que mais se destacaram foram os tratamentos $3(50 \%$ de redução foliar) e 4 (75\% de redução foliar), com 100\% de sobrevivência aos 100 dias. O tratamento 2 (com $25 \%$ de redução foliar), resultou em $99,21 \%$ de sobrevivência e o tratamento 1 ( $0 \%$ de redução foliar) apresentou $92,86 \%$ de sobrevivência, já o tratamento 5 (com $100 \%$ de redução foliar) teve $0 \%$ de sobrevivência, provando que sem a folha, no período de enraizamento, a miniestaca de híbrido de Eucalyptus urophylla var. platyphylla, não pode sobreviver, pois assim há uma pequena produção de fotoassimilados o que resulta em dificuldades na produção de raízes.

\section{Parâmetros gerais}

Analisando o conjunto como um todo, através do contraste de todos os parâmetros morfológicos analisados, que são os mais comuns empregados na seleção de mudas em viveiro, é possível forma de avaliar a possível influência positiva da redução foliar na qualidade das mudas produzidas.

TABELA 1. Média geral dos parâmetros analisados

\begin{tabular}{|c|c|c|c|c|}
\hline \multicolumn{5}{|c|}{ QUADRO GERAL DAS MÉDIAS DOS PARÂMETROS ANALISADOS } \\
\hline Tratamentos & $\begin{array}{l}\text { Altura } \\
\text { (cm) }\end{array}$ & $\begin{array}{l}\text { Diâmetro } \\
(\mathrm{mm})\end{array}$ & $\begin{array}{c}\text { Relação } \\
\text { H:DC }\end{array}$ & $\begin{array}{c}\text { Sobrevivência } \\
\text { (\%) }\end{array}$ \\
\hline 1 & 36,11 & 3,4 & 10,85 & 0,93 \\
\hline 2 & 37,42 & 3,81 & 10,14 & 0,99 \\
\hline 3 & 28,02 & 2,95 & 9,75 & 1 \\
\hline 4 & 24,96 & 2,46 & 10,47 & 1 \\
\hline 5 & 0 & 0 & 0 & 0 \\
\hline
\end{tabular}

FONTE: Próprio Autor, (2018). 
Nota-se que tratamento 2 (com 25\% de redução foliar) obteve os melhores resultados de altura e diâmetro do colo. A variável relação $(H: D)$ alcançou os maiores resultados no tratamento $1(\mathrm{com} 0 \%$ de redução foliar). Em relação à sobrevivência os tratamentos 3 e 4 apresentaram os melhores resultados, no entanto, o tratamento 2 também apresentou uma alta taxa de sobrevivência de mudas com $99,21 \%$.

De acordo Souza et al. (2013) um maiores temores na utilização de miniestacas com folhas inteiras em razão ao maior contato entre as folhas, conciliado com temperaturas elevadas e umidade no período de verão, que poderiam favorecer ao desenvolvimento de doenças, principalmente, na casa de vegetação.

\section{CONCLUSÃO}

Com base nos resultados apresentados e discutidos, pode-se constatar que nas condições em que foi realizado o experimento, o tratamento 2 (com $25 \%$ de redução de área foliar) de maneira geral foi o que se sobressaiu entre os demais tratamentos, podendo assim ser recomendado para a propagação de híbridos de Eucalyptus urophylla var. platyphylla.

\section{REFERÊNCIAS}

ALFENAS.A.C.; ZAUZA E.A.; MAFIA R.G.; ASSIS T.F. Clonagem e Doenças do Eucalipto. 2ed. Viçosa, MG: UFV; 2009.

BATISTA, A. F.; DOS SANTOS, G. A.; DUQUE SILVA, L.; FREITAS QUEVEDO, F \& DE ASSIS, T. F. Influência da Arquitetura Foliar de miniestacas na propagação de Eucalyptus. Revista Árvore, v. 38, n. 5, 2014. Disponível em:< http://www.scielo.br/pdf/rarv/v38n5/v38n5a06.pdf>.

BENIN, C. C.; PERES, F. S. B \& DE OLIVEIRA GARCIA, F. A. Enraizamento de miniestacas apicais, intermediárias e basais em clones de Eucalyptus benthamii. Floresta, v. 43, n. 3, p. 421-428, 2013. Disponível em:< http://revistas.ufpr.br/floresta/article/view/28542>. doi: ttp://dx.doi.org/10.5380/rf.v43i3.28542

BRONDANI, G. E.; BACCARIN, F. J. B.; BERGONCI, T.; GONÇALVES, A. N \& DE ALMEIDA, M. Miniestaquia de Eucalyptus benthamii: efeito do genótipo, AIB, zinco, boro e coletas de brotações. Cerne, v. 20, n. 1, p. 147-156, 2014.Disponível em:< http://www.cerne.ufla.br/site/index.php/CERNE/article/view/971/744>.

BRONDANI, G. E.; WENDLING, I.; DE ARAUJO, M. A \& PIRES, P. P. Ácido indolbutírico em gel para o enraizamento de miniestacas de Eucalyptus benthamii Maiden \& Cambage $x$ Eucalyptus dunnii Maiden. Scientia agraria, v. 9, n. 2, p. 153158, 2008. Disponível em:< http://revistas.ufpr.br/agraria/article/view/10962>. doi: http://dx.doi.org/10.5380/rsa.v9i2.10962

BUTRINOWSKI, R. T.; BUTRINOWSKI, I. T.; DOS SANTOS, E. L.; PICOLOTTO, P. R.; PICOLOTTO, R. A \& SANTOS, R. F. Disponibilidade hídrica no desenvolvimento inicial de mudas de Eucalyptus grandis em ambiente protegido. Acta Iguazu, v. 2, n. 
3, p. 84-93, 2013. Disponível em:< http://erevista.unioeste.br/index.php/actaiguazu/article/view/8629/6370>.

CARNEIRO, J.G.A. Produção e controle de mudas florestais. $1^{\circ}$ ed. Viçosa MG: Folha de Viçosa 1995.

CORREIA, A. C. G.; XAVIER, A.; DIAS, P. C.; TITON, M \& SANTANA, R. C. Redução foliar em miniestacas e microestacas de clones híbridos de Eucalyptus globulus. Revista Árvore, v. 39, n. 2, p. 295-304, 2015. Disponível em:< http://www.locus.ufv.br/handle/123456789/16499>.

doi: http://dx.doi.org/10.1590/0100-67622015000200009

DIAS, P. C.; XAVIER, A.; SILVA DE OLIVEIRA, L.; GUIEIRO CORREIA, A. C \& ANDRÉ BARBOSA, G. Tipo de miniestaca e de substrato na propagação vegetativa de Angico-vermelho (Anadenanthera macrocarpa (Benth.) Brenan). Ciência

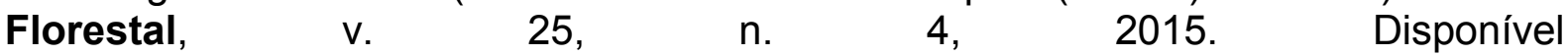
em:<https://periodicos.ufsm.br/cienciaflorestal/article/view/20593>. doi: http://dx.doi.org/10.5902/1980509820593

ENGEL, M. L.; HIGA, A. R.; ALCANTARA, G. D.; JUNIOR, P. C.F \& SOARES, I. D. Enraizamento de miniestacas de diferentes clones de Acacia mearnsii De Wildeman com aplicação de AIB. Revista Espacios, v. 38, n. 23, p. 8-19, 2017. Disponível em:< http://www.revistaespacios.com/a17v38n23/a17v38n23p08.pdf >.

FERREIRA, D. H. A. A.; DOS SANTOS LELES, P. S.; MACHADO, E. C.; DE ABREU, A. H. M \& ABILIO, F. M. Crescimento de clone de Eucalyptus urophylla $x$ E. grandis em diferentes espaçamentos. Floresta, v. 44, n. 3, p. 431-440, 2014. Disponível em:< http://revistas.ufpr.br/floresta/article/view/32188>. doi: http://dx.doi.org/10.5380/rf.v44i3.32188

FREITAS, A. F. D.; PAIVA, H. N. D.; XAVIER, A \& NEVES, J. C. L. Productivity of ministumps and rooting of minicuttings of hybrids of eucalyptus globulus labill in response to nitrogen. Ciência Florestal, v. 27, n. 1, p. 193-202, 2017. Disponível em:< http://www.scielo.br/scielo.php?pid=S198050982017000100193\&script=sci_arttext>. doi: http://dx.doi.org/10.5902/1980509826458

GOMES, J. M.; COUTO, L.; LEITE GARCIA, H.; XAVIER, A \& RIBEIRO, L.R. S. Parâmetros morfológicos na avaliação da qualidade de mudas de Eucalyptus grandis. Revista Árvore, v. 26, n. 6, 2002. Disponível em:< http://www.scielo.br/pdf/rarv/v26n6/a02v26n6.pdf>.

JOHNSON, J.D.; CLINE, P.M. Seedling quality of southern pines. In: Dureya ML, Paiva HN, Gomes JM. Viveiros florestais. UFV: Viçosa; 1991.

LAfETÁ, B. O.; MATOS, M. P.; LAGE, P.; FERRARO, A. C \& PENIDO, T. M. A. Ácido indol-3-butírico (AIB) no enraizamento de estacas de fedegoso gigante. Pesquisa Florestal Brasileira, v. 36, n. 88, p. 489-496, 2016. Disponível em:< https://pfb.cnpf.embrapa.br/pfb/index.php/pfb/article/view/1084/543 >. doi: 10.4336/2016.pfb.36.88.1084 
MORAES, C. E.; DE MELO FONSECA, R. C \& RUI, M. Influência das folhas no enraizamento de miniestacas de híbridos de eucalipto. Nucleus, v. 11, n. 1, 2014. Disponível em:< http://www.nucleus.feituverava.com.br/index.php/nucleus/article/view/995>. doi: http://dx.doi.org/10.3738/1982.2278.995

NEUBERT, V. D. F.; XAVIER, A.; PAIVA, H. N. D.; DIAS, P. C \& GALLO, R. Production of mini-cuttings and the influence of leaf reduction on rooting of vinhático (Plathymenia foliolosa Benth.) 1. Revista Árvore, v. 41, n. 4, 2017. Disponível em:< http://www.scielo.br/scielo.php?pid=S0100-67622017000400202\&script=sci_arttext>. doi: http://dx.doi.org/10.1590/1806-90882017000400002

OLIVEIRA, T.P.F.; BARROSO, D.G.; LAMÔNICA, K.R.; CARVALHO, V.S \& OLIVEIRA, M. A. Efeito do ácido indol-3-butírico (aib) no enraizamento de miniestacas de ipê-roxo (Handroanthus heptaphyllus Mattos). Ciência Florestal, v. 25, n. $\quad 4,4015.4$ Disponível https://periodicos.ufsm.br/cienciaflorestal/article/view/20666 doi: http://dx.doi.org/10.5902/1980509820666

PAIVA, H. N.; GOMES, J. M. Propagação vegetativa de espécies florestais. 3 ed. Viçosa: UFV, 2011. 52 p.

RAASCH, L. D.; BONALDO, S. M \& OLIVEIRA, A. A. F. Bacillus subtilis: enraizamento e crescimento de miniestacas de eucalipto em Sinop, norte de Mato Grosso. Bioscience Journal, v. 29, n. 5, 2013. Disponível em:< http://www.seer.ufu.br/index.php/biosciencejournal/article/view/15179/13290>.

ROCHA, J. H. T.; BACKES, C.; BORELLI, K.; PRIETO, M. R.; SANTOS, A. J. M \& DE OLIVEIRA GODINHO, T. Produtividade do minijardim e qualidade de miniestacas de um clone híbrido de Eucalyptus grandis $x$ Eucalyptus urophylla (I224) em Função de Doses de Nitrogênio. Ciência Florestal, v. 25, n. 2, p. 273-279, 2015. Disponível em:< https://periodicos.ufsm.br/cienciaflorestal/article/view/18411>. doi: http://dx.doi.org/10.5902/1980509818411

SANTANA, R. C.; DUTRA, T. R.; CARVALHO NETO, J. P.; NOGUEIRA, G. S.; GRAZZIOTTI, P. H \& BARROS FILHO, N. F. D. Influence of leaf areareduction on clonal production of Eucalyptusseedlings. Cerne, v.16, n.3, p.251-257, 2010.

Disponível em:< http://www.scielo.br/scielo.php?pid=S0104$77602010000300001 \&$ script=sci_arttext\&tlng=pt>.

doi: http://dx.doi.org/10.1590/S0104-77602010000300001

SCHUMACHER, M. V.; CORREAA, R. S.; VIERA, M \& ARAÚJO, E. F. D. itter production and decomposition in Eucalyptus urophylla $\mathrm{x}$ Eucalyptus globulus maidenii stand. Cerne, v. 19, n. 3, p. 501-508, 2013. Disponível em:< http://www.scielo.br/scielo.php?

pid=S010477602013000300018\&script=sci_arttext\&tlng=es $>$.

doi: http://dx.doi.org/10.1590/S0104-77602013000300018 
SOUZA, C. C.; XAVIER, A.; LEITE, F. P.; SANTANA, R. C \& LEITE, H. G. Padrões de miniestacas e sazonalidade na produção de mudas clonais de Eucalyptus grandis Hill X E. urophylla ST Black. Revista Árvore, v. 37, n. 1, p. 67-77, 2013. Disponível em:<

http://www.ingentaconnect.com/content/doaj/01006762/2013/00000037/00000001/art 00016>. doi: https://doi.org/10.1590/S0100-67622013000100008

SPERANDIO, H. V.; CALDEIRA, M. V. W.; GOMES, D. R.; SILVA, A. G \& GONÇALVES, E. O. Qualidade de mudas de Eucalyptus urophylla x Eucalyptus grandis produzidas em diferentes substratos. Engenharia Ambiental: Pesquisa e

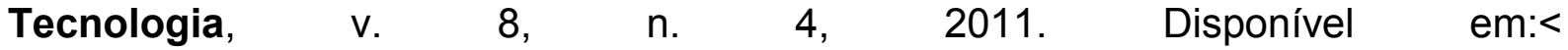
http://ferramentas.unipinhal.edu.br/engenhariaambiental/viewarticle.php? id $=656$ \&layout $=$ abstract $>$.

STUEPP, C. A.; ZUFFELLATO-RIBAS, K. C.; WENDLING, I.; KOEHLER, H. S \& BONA, C. Leaf presence and indolebutyric acid on cuttings rooting of dragon tree. Comunicata Scientiae, v. 6, n. 2, p. 181-193, 2015. Disponível em:< https://comunicatascientiae.com.br/comunicata/article/view/755>.

XAVIER, A.; WENDLING, I.; SILVA R.L. Silvicultura Clonal: princípios e técnicas. $1^{\circ}$ ed. Viçosa MG: UFV; 2009. 